\title{
Correlation between neuroimaging (CT scan) and neurological presentation in antepartum and postpartum eclampsia
}

\author{
Shruti M. Ugran*, Kasturi V. Donimath \\ Department of Obstetrics \& Gynaecology, Karnataka Institute of Medical Sciences, Hubli, Karnataka, India \\ Received: 09 December 2015 \\ Accepted: 07 January 2016 \\ *Correspondence: \\ Dr. Shruti M. Ugran, \\ E-mail: shrutiugran@gmail.com \\ Copyright: (c) the author(s), publisher and licensee Medip Academy. This is an open-access article distributed under \\ the terms of the Creative Commons Attribution Non-Commercial License, which permits unrestricted non-commercial \\ use, distribution, and reproduction in any medium, provided the original work is properly cited.
}

\begin{abstract}
Background: Eclampsia is a pregnancy related condition with high mortality and morbidity along with perinatal mortality and morbidity. The following study is designed to correlate the neurological presentation with neuroimaging (CT scan brain) in antepartum and postpartum eclampsia patients, which will guide in proper management of the patients.

Methods: A prospective study conducted over a period of one year. 100 patients were included in all. The neurological presentation and neuroimaging findings were correlated in all antepartum and postpartum eclampsia patients who met the study criteria. The comparison was done using chi-square test and unpaired student ' $\mathrm{t}$ ' test. Sensitivity, specificity, positive predictive value and negative predictive value were calculated to find the accuracy of neurological presentation in determining the diagnosis and kappa agreement.

Results: Out of the 100 patients studied, 52 had significant CT scan findings. Of these 52, 35 women had neurological signs and symptoms, and 17 cases did not have neurological signs and symptoms $(\mathrm{p}=0.003)$. The sensitivity, specificity, positive predictive value and negative predictive value were found to be $67.31 \%, 62.5 \%$, $66.04 \%$ and $63.83 \%$ respectively and the diagnostic accuracy was found to be $65 \%$.

Conclusions: Evaluation of neurological signs and symptoms in women with eclampsia is an important assessment which helps for the further management. Neuroimaging has limited role in uncomplicated cases. Neuroimaging is indicated in atypical presentation, fatal cases and those resistant to standard anti-eclamptic therapy, where the signs and symptoms fail to predict the likelihood diagnosis.
\end{abstract}

Keywords: Eclampsia, Neuroimaging, Neurological presentation

\section{INTRODUCTION}

Pre-eclampsia and eclampsia are two clinical situations that are exclusively associated with pregnancy. ${ }^{1}$ The incidence of eclampsia is around 1 in 2000 deliveries in developed countries and as high as around 1 in 100 to 1 in 1700 in developing countries. ${ }^{2}$ It causes $14 \%$ stillbirths and $6 \%$ of neonatal deaths. ${ }^{3}$ Eclampsia occurs in antepartum period in $35-45 \%$, intrapartum in $15-20 \%$ and in post-partum period in $30-45 \% .35 \%$ of patients who develop eclampsia have preeclampsia in subsequent pregnancy. ${ }^{4}$ Neurological complications of eclampsia include mental confusion, seizures, cortical blindness, deficits in the visual fields, visual blurring and headaches. At neuroimaging, abnormalities include cortical edema and sometimes intracerebral hemorrhage. At pathology, typically signs include cortical and subcortical hemorrhagic petechiae, mostly in the parieto-occipital region. ${ }^{1} \mathrm{CT}$ and MRI of brain have revolutionized visualization of lesions in eclampsia and other organic conditions. CT is a rapid initial imaging tool preferred to MRI in some conditions, like hemorrhage and space 
occupying lesions, and is complementary to MRI in others. ${ }^{5}$ The present study was planned to assess the utility of CT imaging by correlation of clinical presentation and neuroimaging findings in patients with antepartum and postpartum eclampsia, so as to initiate proper management. CT scanning of the brain, with or without contrast, can exclude cerebral venous thrombosis, intracranial hemorrhage, and central nervous system lesions, all of which can occur in pregnancy and present with seizures. ${ }^{6}$ CT scanning has been found useful in patients who have been involved in trauma, are refractory to magnesium sulphate therapy, or have atypical presentations (seizures $>24$ hours after delivery). Although obtaining a CT scan in eclampsia is not routine, abnormalities have been observed in up to $50 \%$ of women imaged. ${ }^{6}$ Characteristic CT scan findings in eclampsia include cortical hypodense areas, particularly in the occipital lobes, and diffuse cerebral edema, which is believed to correspond to petechial haemorrhages and diffuse edema noted in post-mortem studies. ${ }^{6}$

\section{METHODS}

The present study was conducted in the Department of Obstetrics and Gynaecology, Karnataka Institute of Medical Sciences, Hubli, Karnataka, India from January 2012 to December 2012. This was a prospective study. Women admitted with eclampsia (antepartum or postpartum) under the Department of Obstetrics and Gynaecology, Karnataka Institute of Medical Sciences Hospital, Hubli were included in the study. A total of 100 women with eclampsia (antepartum or postpartum) were studied. All the women presenting with eclampsia (antepartum or postpartum) satisfying selection criteria during the study period were included in the study.

\section{Inclusion criteria}

Women presenting with eclampsia (antepartum or postpartum) with (1) Atleast one episode of seizure in women with $>20$ weeks gestation or $<6$ weeks postpartum with; (2) Blood pressure : >140 mm of $\mathrm{Hg}$ systolic or $90 \mathrm{~mm}$ of $\mathrm{Hg}$ diastolic; (3) Urine albumin of more than $0.3 \mathrm{gm} / \mathrm{L}$.

\section{Exclusion criteria}

- Women who are a known case of chronic Hypertension, Epilepsy.

- Seizures due to metabolic disturbances, space occupying lesions or intracerebral infections.

The study was approved by the Ethical and Research Committee, Karnataka Institute of Medical Sciences, Hubli, India .All the women fulfilling the selection criteria were explained about the nature of the study. A written informed consent was obtained before enrolment. After the enrolment, data such as age, obstetric history, and period of gestation were obtained. Women were evaluated for the clinical presentation including neurological symptoms and signs. Neurological examination was carried out and the findings were recorded. These women were subjected to computed tomography scan (plain and contrast) and the diagnosis was recorded. Antepartum patients underwent CT scanning with an abdominal shield. Those with electrolyte disturbances on the investigation panel, recent history of fever, CT brain showing SOL were excluded from the study.

\section{Outcome variables}

- Neurological presentation.

- Computed tomography (CT) scan findings

- Correlation of neurological presentation and CT scan findings.

\section{Statistical analysis}

The categorical data was expressed as rates, ratios and proportions, and continuous data was expressed as mean \pm standard deviation (SD). The comparison was done using chi-square test and unpaired student ' $t$ ' test. Sensitivity, specificity, positive predictive value and negative predictive value were calculated to find the accuracy of neurological presentation in determining the diagnosis and kappa agreement. While determining the accuracy of neurological presentation with diagnosis, a patient was considered to have neurological signs if she had one or more neurological signs. A probability value ( $\mathrm{p}$ value) of less than 0.050 was considered as statistically significant.

\section{RESULTS}

A total of 100 women with eclampsia (antepartum and postpartum) satisfying selection criteria were studied. The data was analysed and the final results and observations were as follows. Most of the women (50\%) presented with age between 22 to 25 years followed by $\leq 21$ years $(40 \%)$. The mean age of the study population was $22.61 \pm 2.72$ years. $66 \%$ of the women presented with postpartum eclampsia while $34 \%$ had antepartum eclampsia. The mean age in women with antepartum and postpartum eclampsia was comparable (22.65 \pm 2.71 versus $22.59 \pm 2.75$ years; $p=0.922$ ). The gestational age in women with antepartum eclampsia was $35.56 \pm 3.17$ weeks. In those with postpartum eclampsia the mean was found to be $3.82 \pm 1.93$ days postpartum. $84 \%$ of the women had $\leq 3$ episodes of seizures while $16 \%$ of the women had 4 or more episodes. All the women (100\%) had generalized tonic clonic seizures.

As seen in Table 1, the commonest clinical presentation was unconsciousness (35\%). In those with antepartum eclampsia, $61.76 \%$ of the women presented with unconscious state compared to $21.21 \%$ women who had postpartum eclampsia. The other presentations included altered sensorium (14\%), frothing from mouth (11\%) and incontinence $(6 \%)$. 
Table 1: Clinical presentation.

\begin{tabular}{|c|c|c|c|c|c|c|}
\hline \multirow[t]{2}{*}{$\begin{array}{l}\text { Presentati } \\
\text { on }\end{array}$} & \multicolumn{2}{|c|}{$\begin{array}{l}\text { Antepartum } \\
(\mathrm{n}=\mathbf{3 4})\end{array}$} & \multicolumn{2}{|c|}{$\begin{array}{l}\text { Postpartum } \\
(\mathrm{n}=66)\end{array}$} & \multicolumn{2}{|c|}{$\begin{array}{l}\text { Total } \\
(n=100)\end{array}$} \\
\hline & No. & $\%$ & No. & $\%$ & No. & $\%$ \\
\hline $\begin{array}{l}\text { Unconsci } \\
\text { ous }\end{array}$ & 21 & 61.76 & 14 & 21.21 & 35 & 35 \\
\hline $\begin{array}{l}\text { Altered } \\
\text { sensoriu } \\
\mathrm{m}\end{array}$ & 7 & 20.59 & 7 & 10.61 & 14 & 14 \\
\hline Frothing & 7 & 20.59 & 4 & 6.06 & 11 & 11 \\
\hline $\begin{array}{l}\text { Incontine } \\
\text { nce }\end{array}$ & 3 & 8.82 & 3 & 4.55 & 6 & 6 \\
\hline
\end{tabular}

As shown in Table 2, headache was the commonest symptom reported by $42 \%$ of the women. Headache was present more commonly in women with antepartum eclampsia $(52.94 \%)$ compared to women with postpartum eclampsia $(36.36 \%)$. The other common symptoms were blurring of vision $(23 \%)$ and vomiting $(22 \%)$. In the present study, motor paralysis was noted in $7 \%$ cases of which two cases $(5.88 \%)$ had antepartum eclampsia and five cases had postpartum eclampsia (7.58\%). Facial deviation was noted in one case $(2.94 \%)$ of antepartum eclampsia. None of the case had twitching, tingling and numbness, and speech changes.

Table 2: Symptoms.

\begin{tabular}{|c|c|c|c|c|c|c|}
\hline \multirow[t]{2}{*}{ Symptoms } & \multicolumn{2}{|c|}{$\begin{array}{l}\text { Antepartum } \\
(\mathrm{n}=\mathbf{3 4})\end{array}$} & \multicolumn{2}{|c|}{$\begin{array}{l}\text { Postpartum } \\
(n=66)\end{array}$} & \multicolumn{2}{|c|}{$\begin{array}{l}\text { Total } \\
(n=100)\end{array}$} \\
\hline & No. & $\%$ & No. & $\%$ & No. & $\%$ \\
\hline Headache & 18 & 52.94 & 24 & 36.36 & 42 & 42 \\
\hline $\begin{array}{l}\text { Blurring of } \\
\text { vision }\end{array}$ & 11 & 32.35 & 12 & 18.18 & 23 & 23 \\
\hline Vomiting & 11 & 32.35 & 11 & 16.67 & 22 & 220 \\
\hline
\end{tabular}

Most of the women in the study (59\%) were primiparous. Among the women with postpartum eclampsia $56.06 \%$ were primiparous while $43.94 \%$ were multiparous. In those with antepartum eclampsia, $64.71 \%$ were primiparous and $35.29 \%$ were multiparous. The mean systolic BP in antepartum group was $158.24 \mathrm{mmHg}$ and diastolic being $100.82 \mathrm{~mm} \mathrm{Hg}$. The mean systolic BP in postpartum group being $155.54 \mathrm{mmHg}$ and diastolic being $102.03 \mathrm{mmHg}$.

In the present study $17.65 \%$ of the women with antepartum eclampsia were unconscious and $11.76 \%$ were drowsy compared to $4.55 \%$ women, each who had postpartum eclampsia. This difference was statistically significant $(\mathrm{p}=0.029)$ (Table 3$)$.

$29.41 \%$ of the women with antepartum eclampsia were disoriented compared to $9.09 \%$ of the women who had postpartum eclampsia and this difference was significant $(\mathrm{p}=0.009)$ statistically. In the present study, $82.35 \%$ of the women with antepartum eclampsia and $84.85 \%$ with postpartum eclampsia had normal upper and lower limb tone. This difference was statistically not significant $(\mathrm{p}$ 0.747). Decreased upper and lower limb power was noted in $20.59 \%$ of the women with antepartum eclampsia and $16.67 \%$ with postpartum eclampsia. However, this difference was statically not significant, (p 0.629). $20.59 \%$ of the women with antepartum eclampsia and $12.12 \%$ of the cases with postpartum eclampsia had decreased upper and lower limb reflexes and the difference was statistically not significant ( $p$ 0.261). $17.65 \%$ of the women with antepartum eclampsia had decreased sensory system functions for upper and lower limb compared to $6.06 \%$ of women with postpartum eclampsia. However, this difference was statistically not significant $(p=0.067)$. The seventh nerve (facial) palsy was present in one patient each with antepartum $(2.94 \%)$ and postpartum $(1.52 \%)$ eclampsia and the difference was not statistically significant $(\mathrm{p}=0.629)$ (Table 4).

Table 3 : Neurological examination findings consciousness.

\begin{tabular}{|c|c|c|c|c|c|c|}
\hline \multirow[t]{2}{*}{ Findings } & \multicolumn{2}{|c|}{$\begin{array}{l}\text { Antepartum } \\
(\mathbf{n}=\mathbf{3 4})\end{array}$} & \multicolumn{2}{|c|}{$\begin{array}{l}\text { Postpartum } \\
(n=66)\end{array}$} & \multicolumn{2}{|c|}{$\begin{array}{l}\text { Total } \\
(n=100)\end{array}$} \\
\hline & No. & $\%$ & No. & $\%$ & No. & $\%$ \\
\hline Conscious & 24 & 70.59 & 60 & 90.91 & 84 & 84 \\
\hline Drowsy & 4 & 11.76 & 3 & 4.55 & 7 & 7 \\
\hline Unconscious & 6 & 17.65 & 3 & 4.55 & 9 & 9 \\
\hline Total & 34 & 100 & 66 & 100 & 100 & 100 \\
\hline
\end{tabular}

Table 4: Neurological examination findings orientation.

\begin{tabular}{|llclllll|}
\hline \multirow{2}{*}{ Findings } & \multicolumn{2}{l}{$\begin{array}{l}\text { Antepartum } \\
(\mathrm{n}=34)\end{array}$} & \multicolumn{2}{l|}{$\begin{array}{l}\text { Postpartum } \\
(\mathrm{n}=66)\end{array}$} & \multicolumn{2}{l|}{$\begin{array}{l}\text { Total } \\
(\mathrm{n}=100)\end{array}$} \\
\cline { 2 - 7 } & No. & $\%$ & \multicolumn{2}{l|}{ No. } & $\%$ & No. & $\%$ \\
\hline Disoriented & 10 & 29.41 & 6 & 9.09 & 16 & 16 \\
\hline $\begin{array}{l}\text { Well } \\
\text { oriented }\end{array}$ & 24 & 70.59 & 60 & 90.91 & 84 & 84 \\
\hline Total & 34 & 100 & 66 & 100 & 100 & 100 \\
\hline $\mathrm{p}=0.009$ & & & & & & \\
\hline
\end{tabular}

CT scan revealed no abnormal findings in $48 \%$ of the women. In those with abnormal CT scan findings, the commonest diagnosis was CVT with infarct (23\%) followed by infarct (14\%), PRES (6\%), HLE (5\%), CVT $(3 \%)$ and cerebral atrophy $(1 \%)$ (Table 5).

In the present study the commonest neurological presentation in patients of CVT with infarct was headache $(65.22 \%)$, followed by unconsciousness $(47.83 \%)$, altered sensorium and blurring of vision (26.09\% each), motor paralysis $(17.39 \%)$, incontinence and frothing from mouth (13.04\% each). The commonest neurological presentation in patients with infarct was unconsciousness $(50 \%)$, followed by headache $(42.86 \%)$, frothing and blurring of vision (13.04\% each), altered sensorium (28.57\%), palsy (14.29\%), incontinence and 
facial deviation (7.14\% each). Patients with PRES had headache, blurring of vision (33.33\% each), altered sensorium, incontinence and frothing ( $16.67 \%$ each). The neurological spectrum of presentation in patients with hypertensive leucoencephalopathy included unconsciousness (60\%), headache $(40 \%)$, altered sensorium and blurring of vision (20\% each).

Table 5: Computed tomography scan findings.

\begin{tabular}{|c|c|c|c|c|c|c|}
\hline \multirow[t]{2}{*}{ Findings } & \multicolumn{2}{|c|}{ Antepartum (n=34) } & \multicolumn{2}{|c|}{ Postpartum (n=66) } & \multicolumn{2}{|c|}{ Total $(n=100)$} \\
\hline & No. & $\%$ & No. & No. & $\%$ & No. \\
\hline CVT with infarct & 7 & 20.59 & 16 & 24.24 & 23 & 23 \\
\hline Infarct & 7 & 20.59 & 7 & 10.61 & 14 & 14 \\
\hline Posterior reversible encephalopathy syndrome & 2 & 5.88 & 4 & 6.06 & 6 & 6 \\
\hline Hypertensive leucoencephalopathy & 3 & 8.82 & 2 & 3.03 & 5 & 5 \\
\hline Cerebral vein thrombosis & 1 & 2.94 & 2 & 3.03 & 3 & 3 \\
\hline Cerebral atrophy & 0 & 0.00 & 1 & 1.52 & 1 & 1 \\
\hline No abnormality detected & 14 & 41.18 & 34 & 51.52 & 48 & 48 \\
\hline Total & 34 & 100 & 66 & 100 & 100 & 100 \\
\hline
\end{tabular}

In this study, of the 52 cases with CT diagnosis, 35 women had neurological signs and symptoms and 17 cases did not have neurological signs and symptoms $(\mathrm{p}=0.003)$. The sensitivity, specificity, positive predictive value and negative predictive value were found to be $67.31 \%, 62.5 \%, 66.04 \%$ and $63.83 \%$ and the diagnostic accuracy was found to be $65 \%$ (Table 6).

Kappa $=0.298 ;$ SE of kappa $=0.096 ; 95 \%$ confidence interval : From 0.111 to 0.486 The strength of agreement is considered to be 'fair'.

Table 6: Accuracy of neurological signs and symptoms in determining the CT diagnosis.

\begin{tabular}{|llll|}
\hline $\begin{array}{l}\text { Neurological signs } \\
\text { and symptoms }\end{array}$ & \multicolumn{2}{l}{ CT findings } & Total \\
\cline { 2 - 3 } & Positive & Negative & \\
\hline Present & 35 & 18 & 53 \\
\hline Absent & 17 & 30 & 47 \\
\hline Total & 52 & 48 & 100 \\
\hline p=0.003 & & & \\
\hline Sensitivity & Specificity & PPV & NPV \\
\hline 67.31 & 62.50 & 66.04 & 63.83 \\
\hline
\end{tabular}

\section{DISCUSSION}

Pre-eclampsia is a complex disorder characterized by pregnancy induced hypertension, proteinuria occurring after twenty weeks of pregnancy. Neurologic manifestations of pre-eclampsia include headache, confusion, hyperreflexia, visual hallucinations and blindness. Eclampsia has been defined as the occurrence of convulsion, not caused by any coincidental neurologic disease (e.g. epilepsy) in a woman whose condition also meets the criteria for pre-eclampsia. ${ }^{7}$ A common cause of death in eclampsia is central nervous system pathology such as intracerebral haemorrhage or massive cerebral oedema.

This prospective study was conducted from January 2012 to December 2012 in the Department of Obstetrics and Gynaecology, Karnataka Institute of Medical Sciences Hospital, Hubli. A total of 100 women with eclampsia (antepartum or postpartum) were studied. More than half of the study population was (50\%) aged between 22 to 25 years and $40 \%$ of the women were aged $\leq 21$ years. A similar study from New Delhi reported that majority of patients belonged to age group between 20 to 25 years $(60 \%)$ which was comparable with the present study. The mean age in this study was $22.61 \pm 2.72$ years. A similar study from Tumkur, Karnataka reported the mean maternal age as 23.89 years (range $18-30$ years). ${ }^{5}$ In this study, $66 \%$ of women had postpartum eclampsia while $34 \%$ had antepartum eclampsia. These results were also similar to the epidemiological and interventional studies conducted in the developing countries like Nepal and Zimbabwe. $^{2,8}$ Most cases of eclampsia presented in the third trimester of pregnancy, with about $80 \%$ of eclamptic seizures occurring intrapartum or within the first 48 hours following delivery. Rare cases have been reported prior to 20 weeks gestation or as late as 23 days postpartum. In this study, $59 \%$ of the women were primiparous. Among them, $64.71 \%$ had antepartum eclampsia while $56.06 \%$ had postpartum eclampsia and the same observed in $35.29 \%$ and $43.94 \%$, respectively, of women with multiparity. These findings were consistent with a study from New Delhi which reported most of their patients as primiparous (56\%). ${ }^{9}$ In the present study majority (84\%) of the women had less than or equal to 3 episodes of seizures and in the remaining (16\%) four or more episodes were noted. The seizure type in all the women (100\%) was generalized tonic clonic seizures. Similar to the present study, a series of eight cases reported seizure onset was more in prepartum 
(5 cases) than postpartum (3 cases) and all had generalised tonic clonic seizures.

The pathophysiology of eclampsia is explained by two polarized theories. ${ }^{10}$ The first called 'overregulation', intense cerebral vasospasm due to explosive increase in blood pressure results in microischemic damage to bloodbrain barrier leading to cytotoxic edema. The second called 'breakthrough', loss of autoregulation with resultant dilation leading to subsequent vasogenic edema. Both theories may be operative in some eclamptics. Endothelial damage, abnormal placentation, imbalance between vasodilatory and vasoconstrictive prostaglandins are some proposed triggers for vasospasm. ${ }^{11}$ Predilection of symptoms and neuroimaging findings in posterior circulation is explained by more anterior sympathetic innervation.

In this study the commonest clinical presentation was unconsciousness $(35 \%)$. The other presentations included altered sensorium (14\%), frothing from the mouth (11\%) and incontinence $(6 \%)$. The unconscious state was more common in those with antepartum eclampsia $(61.76 \%)$.

In the present study, the commonest symptom was headache reported by $42 \%$ of the women. The other common symptoms were blurring of vision (23\%) and vomiting $(22 \%)$. The headache was present more commonly in women with antepartum eclampsia $(52.94 \%)$. Motor paralysis was noted in $7 \%$ cases. Facial deviation was noted in one case $(2.94 \%)$ of antepartum eclampsia. None of the women had twitching, tingling and numbness, and speech changes. On neurological examination, significantly higher number of women with antepartum eclampsia were unconscious (17.65\%) and drowsy $(11.76 \%)(\mathrm{p}=0.029)$. With regard to orientation, significantly higher number of women $(29.41 \%)$ with antepartum eclampsia was disoriented compared to women with postpartum eclampsia $(9.09 \%) \quad(\mathrm{p}=0.009)$. The upper and lower limb tone was found to be decreased in $17.65 \%$ women with antepartum eclampsia and $13.15 \%$ with postpartum eclampsia $(\mathrm{p}=0.747)$. Similarly upper and lower limb power was decreased in $20.59 \%$ of the women with antepartum eclampsia and $16.67 \%$ with postpartum eclampsia $(\mathrm{p}=0.629)$. The upper and lower limb reflexes were decreased in $20.59 \%$ of the women with antepartum eclampsia and $12.12 \%$ of the cases with postpartum eclampsia $(p=0.261)$. The sensory system functions were impaired in upper and lower limb among $17.65 \%$ of the women with antepartum eclampsia compared to $6.06 \%$ of women with postpartum eclampsia $(p=0.067)$. One case of the seventh nerve (facial) palsy each was noted in women with antepartum $(2.94 \%)$ and postpartum $(1.52 \%)$ eclampsia $(\mathrm{p}=0.629)$. A similar study ${ }^{9}$ from New Delhi reported headache as the most common presenting symptom in $19(76 \%)$ of patients, while $11(44 \%)$ of patients had slurring of speech and 8 $(32 \%)$ of patients were disoriented, had altered consciousness when examined within 48 hours of seizure onset. Visual disturbances were seen in $15(60 \%)$ of patients in the form of blurring of vision, hemianopsia, nystagmus and cortical blindness. Majority of them experienced only blurring of vision with no visual field defect. Other than visual disturbances, 5 (20\%) of the study patients developed focal neurological deficit as well. 3 patients developed ataxia, dysarthria and disconjugate gaze after generalized seizures, one patient developed hemiparesis and the other one had asymmetrical reflexes (left > right). Another study ${ }^{5}$ from Tumkur, Karnataka reported $75 \%$ of patients had atleast one premonitory symptom. Headache was the most common premonitory symptom present in $71 \%$. Other studies by Lubarsky, and Chames reported $83 \%$ and $87 \%$ of patients with headache. ${ }^{12,13}$

Modalities such as CT enable early noninvasive diagnosis of CVT. Simple unenhanced CT or preferably MR imaging allows safe confirmation of pituitary apoplexy. Furthermore, even when the imaging changes are less specific, knowledge of likely possibilities will lead to more appropriate earlier use of imaging. ${ }^{14}$

In this study CT scan revealed normal findings in $48 \%$ of the women. In those with abnormal CT scan findings the commonest diagnosis was CVT with infarct $(23 \%)$ followed by infarct (14\%), PRES (6\%), HLE (5\%), CVT $(3 \%)$, cerebral atrophy $(1 \%)$. The commonest neurological presentation in patients with CVT with infarct was headache $(65.22 \%)$, followed by unconsciousness $(47.83 \%)$. In most instances brain CT in eclamptics might be normal due to temporal relationship of scan to seizure. Neuroimaging within a short time after seizure in eclamptics may yield more abnormalities, presumably due to transient nature of lesions. Most common lesions detected on CT in eclampsia are focal areas of cerebral edema in subcortical white matter of parietal and occipital areas. ${ }^{5}$ A study from Tumkur, Karnataka, India reported $46.4 \%$ (13) of women had other noneclamptic organic causes for postpartum seizures. $28.6 \%$ (8) of postpartum seizures were due to CVT. ${ }^{5}$

In this study, 52 cases had CT findings. Among these significantly higher number women, i.e. 35 women had neurological signs and symptoms and 17 cases did not have neurological signs and symptoms $(\mathrm{p}=0.003)$. The sensitivity, specificity, positive predictive value and negative predictive value were found to be $67.31 \%$, $62.5 \%, 66.04 \%$ and $63.83 \%$ and the diagnostic accuracy was found to be $65 \%$. The kappa value showed fair strength of agreement (Kappa value - 0.298; SE of $\mathrm{kappa}=0.096 ; 95 \%$ confidence interval: From 0.111 to 0.486) suggesting fair correlation between the neurological signs and symptoms and CT diagnosis. These findings suggest that, the signs and symptoms at admission predict the neurological involvement and help to predict the likely diagnosis. A prospective observational study was conducted in Safdarjang Hospital, New Delhi, India to compare CT and MRI findings of eclampsia patients with respect to neurological signs and symptoms. ${ }^{9}$ It was reported that 
MRI was found to be co-relating more than CT with the neurological presentation and had $90 \%$ sensitivity and $100 \%$ sensitivity, respectively. Study concluded that, magnetic resonance imaging abnormalities in eclampsia correlate well with clinical findings as compared to CT and can be better imaging modality in eclampsia patients. In contrast, a study from Tumkur, Karnataka, India was conducted to correlate clinical and radiologic findings, to determine whether brain tomography affects management and routinely indicated in uncomplicated postpartum eclampsia and to differentiate it from other potentially treatable conditions. ${ }^{5}$ It was concluded that, despite many abnormalities seen on imaging studies, some are incidental and transient, without chronic neurologic sequelae. Thus, neuroimaging is indicated in atypical and fatal cases where specific therapy may be required.

The limitations of the study were smaller sample size which limited the study from evaluating commonest neurological signs and symptoms in differential diagnosis, and diagnosis specific accuracy could not be evaluated due to the wide spectrum of clinical presentation and smaller sample size. Further studies including diagnosis of specific neurological manifestations would emphasize the precise clinical presentations in women with eclampsia.

\section{CONCLUSIONS}

Neuroimaging is indicated in atypical, fatal cases and those resistant to standard anti-eclamptic therapy, where signs and symptoms fail to predict the likelihood diagnosis.

\section{ACKNOWLEDGEMEMTS}

Authors would like to thank Department of Radio diagnosis, KIMS, Hubli, Karnataka, India.

\section{Funding: No funding sources}

Conflict of interest: None declared

Ethical approval: The study was approved by the Institutional Ethics Committee

\section{REFERENCES}

1. Kuntz GA, Renato M, Rodrigues CA. Hellp syndrome, reversible posterior leukoencephalopathy syndrome and eclampsia. Arq Neuro-Psiquiatr. 2009;67(4):1103-5.
2. Mishra R. Ian Donald's practical obstetric problems. $6^{\text {th }}$ ed., New Delhi; Advert Arnold B I Publication; 2007.

3. Choudhary A. Eclampsia a hospital based retrospective study. Kathmandu University Med J. 2003;1(4):237-41.

4. Arias F, Duftary SN, Bihndi AG. Practical Guide to high risk pregnancy and delivery. $3^{\text {rd }}$ ed., Noida; Elsevier. 2008.

5. Kokila MS, Dwivedi AD. Correlation of Clinical and Neuroimaging Findings affecting Management in Postpartum Eclampsia: A Prospective Study. J South Asian Federation Obstet Gynaecol. 2011;3(3):12530.

6. Ross MG, Ramus RM. Eclampsia. Access online from 2013.

7. Chakravarty A, Chakrabarti SD. The neurology of eclampsia: some observations. Neurol India. 2002;50:128

8. Majoko F, Mujaji C. Maternal outcome in eclampsia at Harare Maternity Hospital. Cent Afr J Med 2001;47(5):123-8.

9. Jindal MA, Gaikwad HS, Hasija BD, Vani K. Comparison of neuroimaging by CT and MRI and correlation with neurological presentation in eclampsia. Int J Reprod Contracept Obstet Gynecol. 2013;2(1):83-7.

10. Cunningham FG, Twickler D. Cerebral edema complicating eclampsia. Am J Obstet Gynecol. 2000;182:94-100.

11. Felz MW, Barnes DB, Figueroa RE. Late postpartum eclampsia 16 days after delivery: Case report with clinical, radiologic and pathophysiologic correlations. J Am Board Fam Pract. 2000;13(1):3946.

12. Lubarsky SL, Barton JR, Friedman SA, Nasreddine S, Ramadan MK, Sibai BM. Late postpartum eclampsia revisited. Obstet Gynecol. 1994;83:502-5.

13. Chames MC, Livingston J, Invester TS, Barton JR, Sibai BM. Late postpartum eclampsia : a preventable disease? Am J Obstet Gynecol. 2002;186:1174-7.

14. Zak IT, Dulai HS, Kish KK. Imaging of neurologic disorders associated with pregnancy and the postpartum period. Radiographics. 2007;27(1):95108.

Cite this article as: Ugran SM, Donimath KV.

Correlation between neuroimaging (CT scan) and neurological presentation in antepartum and postpartum eclampsia. Int J Reprod Contracept Obstet Gynecol 2016;5:419-24. 